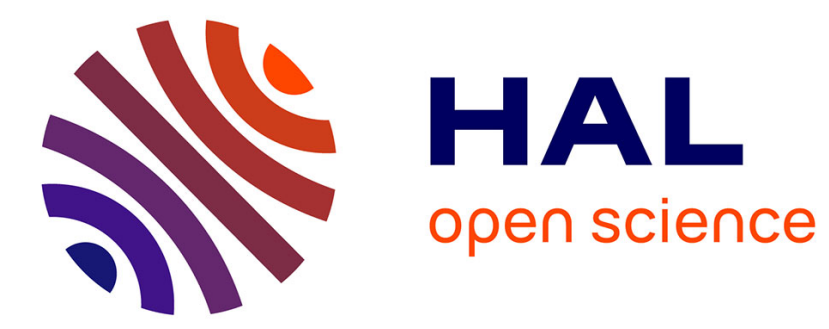

\title{
RECENT RESULTS ON SOFT X-RAY AMPLIFICATION BY LITHIUM-LIKE IONS IN PLASMAS
}

\author{
A. Carillon, A. Klisnick, G. Jamelot, B. Gauthé, F. Gadi, P. Jaeglé
}

\section{- To cite this version:}

A. Carillon, A. Klisnick, G. Jamelot, B. Gauthé, F. Gadi, et al.. RECENT RESULTS ON SOFT XRAY AMPLIFICATION BY LITHIUM-LIKE IONS IN PLASMAS. Journal de Physique Colloques, 1988, 49 (C1), pp.C1-247-C1-250. 10.1051/jphyscol:1988152 . jpa-00227472

\section{HAL Id: jpa-00227472 https://hal.science/jpa-00227472}

Submitted on 1 Jan 1988

HAL is a multi-disciplinary open access archive for the deposit and dissemination of scientific research documents, whether they are published or not. The documents may come from teaching and research institutions in France or abroad, or from public or private research centers.
L'archive ouverte pluridisciplinaire HAL, est destinée au dépôt et à la diffusion de documents scientifiques de niveau recherche, publiés ou non, émanant des établissements d'enseignement et de recherche français ou étrangers, des laboratoires publics ou privés. 


\title{
RECENT RESULTS ON SOFT X-RAY AMPLIFICATION BY LITHIUM-LIKE IONS IN PLASMAS
}

\author{
A. CARILLON, A. KLISNICK, G. JAMELOT, B. GAUTHE, F. GADI and \\ P. JAEGLÉ \\ Laboratoire de spectroscopie Atomigue et Ionique, Bât. 350 , \\ Université Paris-Sud, F-91405 Orsay Cedex, France \\ and GILM, Ecole Polytechnique, F-91128 Palaiseau cedex, France
}

\begin{abstract}
RESUME. Nous avons montrē que plusieurs transitions des ions lithiumoides donnent naissance $\bar{a}$ des inversions de population qui se produisent au cours de la recombinaison de plasmas-laser /1/. La transition $3 \mathrm{~d}-5 \mathrm{f}$ s ituée à $105.7 \mathrm{~A}$ a fait 1 'objet d'une étude détaillée qui révèle l'existence d'un gain passant par une valeur maximum d'environ $2 \mathrm{~cm}^{-1}$ près de $6 \mathrm{~ns}$ après le somet de 1 'impulsion laser dont la durẻe est de 2ns. Cet te êtude a été récemment étendue à la raie $3 d-4 f$ s ituée à 154.7

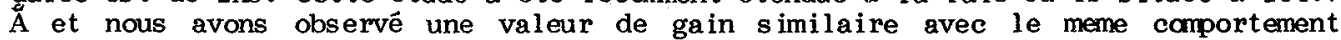
temporel. De plus, en suivant des prévisions fournies par des calculs effectués pour des ions de $\mathrm{Z}$ plus élevé $/ 2 \%$, nous avons étudié la transition $3 d-5 \mathrm{f}$ de $\mathrm{s}^{1} \mathrm{f}^{\mathrm{s}} \mathrm{i}$ tuée à 65.2 A. Nous trouvons pour cette raie une valeur de gain vois ine de $1 \mathrm{~cm}^{-1}$ ce qui constitue le premier résultat obtenu jusqu'ici à une auss i courte longueur d'onde.
\end{abstract}

\begin{abstract}
We have shown that several transitions of Li-like ions give rise to population inversions during the recombination of laser-plasmas $/ 1 /$. An extensive study has been made for the $3 d-5 f$ transition lying at $105.7 \AA$. It has shown a gain coefficient with a maximum around $2 \mathrm{~cm}^{-1}$ occuring about 6 nanosecond after the top of the 2-ns laser pulse. We extended recently this $s$ tudy to the $3 d-4 f$ line ar $154.7 \AA$ and we observed a similar value of gain with the same temporal behaviour. Moreover, following calculafed predictions for higher-Z igns $12 \%$, we studied the $3 d-5 f$ transition of $S^{13 t}$ which takes place at $65.2 \AA$. This study gives the first prel iminary evidence of a gain coefficient of about $1 \mathrm{~cm}^{-1}$.
\end{abstract}

INIRCDUCTION: The rapid cooling of hot laser plasmas in fast expans ion is henceforth known as able to give $r$ ise to amplification of radiation in the $X-U V$ range, due to recombination processes occuring in multicharged ions. The first evidence of such a type of amplification was reported by our group in $1978 / 3 /$. This observation was made on an alumimum $l$ ine situated at $105.7 \AA$ which was unknown at this $t$ ime. It was then identified as the 5f-3d transition of Li-like ion /4/. Later on, $t$ ime integrated, then time resolved measurements have demons trated gains up to $3 \mathrm{~cm}^{-1} / 1 /$ in good agreement with the predictions of theoretical calculations us ing new atomic deta and plasma hydrodynamics $12,5,6 /$. In an aluminum plasma this modeling reveals ga in to be expected also for the $4 f-3 d$ and $5 f-4 d$ transitions situated respectively at 154.6 and $334 \AA$, in all cases a few nanaoseconds after the top of the laser pulse (the duration of which is of the order of $1 \mathrm{~ns}$ ), i.e. during the cooling phase of the plama when recombination takes place.

EXPERIMENTS. For achieving a lasing action one must try to obtain the highest possible GxL product, where $G$ is the gain (per unit length) and $L$ the length of the plasma. This latter co ndition strictly depends on the energy available in the laser pulse. Thus we are now able to produce plasmas as long as $2 \mathrm{~cm}$ with fluxes higher than $10 \mathrm{GW} / \mathrm{cm}$. This is obtained by mixing the two laser beams with the help of a special optical mounting in the way of doubling the energy available /7/. With regard to the increasing of gain itself one must consider different effects as the curation and the wavelength of the laser pulse or the geometry of the target and of its irradiation. In this paper we shall compare the results we have obtained in two kinds of experiments where quite different experimental conditions have been used. In Palaiseau we use one-sided irradiation at $1.054 \mu$ along a focal line on mass ive planar targets with laser pulses comprised between 0.6 and $20 \mathrm{~ns}$. Line focus is obtained by using two crossed cylindrical lenses. The 1 m-grazing incidence 
planar targets with laser pulses comprised between 0.6 and $20 \mathrm{~ns}$. Line focus is obtained. by using two crossed cylindrical lenses. The $1 \mathrm{~m}$-grazing incidence spectrometer uses a 3,600 groves $/ \mathrm{mm}$ grating. But recently a new type of experiment has been developped at Rutherford Laboratory in the frame of a collaboration with our group $/ 8 /$. There the target, which is constituted by a Carbon $f$ iber $7 \mu-w i d e$ coated with $3500 \AA$ of Alumimu, is irradiated symetrically at $0.53 \mu$ along a focal ine by the 120 ps pulse of the Vulcan laser system. In this case, three $7 \mathrm{~mm}-1$ ong line foci are provided by of $f-a x$ is reflection from spherical mirrors. Plasma lengths of 14 or $21 \mathrm{~mm}$ can be obtained by combination of these lines. The spectrograph is of a flat field type.

Beyond the above mentionned differences both experiments also differ in the way gain measurements are performed. In the first case ( $\mathrm{fig} \cdot 1$ ), gain is calculated considering radiation transfer from the intensity ratio between two plasmas of different length (one couple is sufficient). Moreover, by coupling an optical multiplier analyzer at the rear part of the stregk camera, data can be treated on line upon a wide enough range of wavelength ( $3 \AA$ ). Thus an absorption-gain curve versus wavelength is obtained extending far beyond the width of the line under

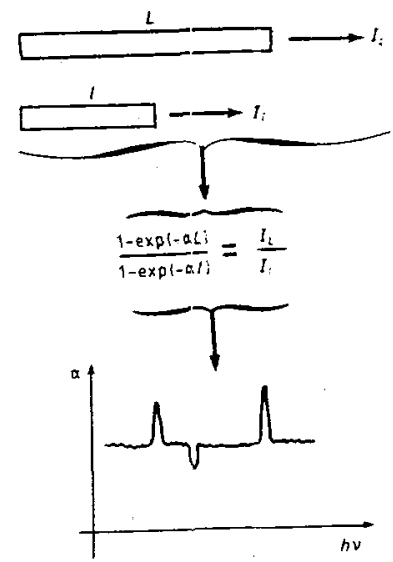

investigation. On the other hand, in the Rutherford experiment, gain is deduced by fitting an exponential curve to the variation of the output intensity with the increasing lengths of several plasmas (more than two are necessary). Since here a photographic plate is used behind the streak and due to low resolution of the flat field spectrometer intensity measurements are made only at the top of the $l$ ines.

RESULTS AND DISOUSSION. Typical results obtained at 105.7 and $154.6 \quad \AA$ are represented in fig.2 (Palaiseau) and in fig.3 (Rutherford). Both time resolved experiments reveal pasitive gain values to be obtained as well for the $5 \mathrm{f}-3 \mathrm{~d}$ transition at 105.7 as for the $4 f-3 d$ at Figure 1. Sketch of the experimental method $154.6 \AA$. But gain values are found of absorption coef $f$ icient measurement in Palaiseau. fibre experiment $\left(3 \mathrm{~cm}^{-1}\right)$ than with the mass ive target one ( 1 to $2 \mathrm{~cm}^{-1}$ ). This can be easily understood if one considers

that in the first case shorter pulses are used ( 120 ps). From a theoretical point of view this leads to a faster cooling of the plasma and favourises inversions. Nevertheless, with mass ive targets, attempts at measuring a gain have always been unsuccessful when using shorter pulses (600 ps instead of $2 \mathrm{~ns})$. Reasons of this discrepancy with theory perhaps can be found in radiation trapping phenomena. Indeed, another feature of the mass ive target experiment is that values of gain obtained seep to decrease when the plasma length increases. For instance a gain value up to $3 \mathrm{~cm}^{-1}$ has been measured with a couple of plasmas of 8 and $3.7 \mathrm{~mm}$ whereas, with plasma lengths of 20 and $9 \mathrm{~mm}$, gain is only about $0.8 \mathrm{~cm}^{-1}$. Let us consider the simpl if ied scheme of Lithium-like atamic structure presented on fig.4. It is clear that the strong electric dipole transition $3 \mathrm{~d}_{3 / 2}-2 \mathrm{p}_{1}$ plays an important role in the population inversion scheme by depopilating the fower level las ing transition as far as no other process is able to repopulate this $3 d$ level. As a matter of fact the optical thickness of plasme increases with length and then absorption processes $2 p-3 d$ can reduce the effective rate of desexcitation of the $3 d$ level. With this in mind, absence of gain at 600 ps can be explained by the fact that, in this case, simulations show inversions to be present at shorter distances from the target surface than at $2 \mathrm{~ns}$, in a relatively dense plasma zone. Radiation trapping can then outshine inversion. On the other hand in fibre experiments one can expect radiation trapping in $3 \mathrm{~d}$ level to be avoided, due to a better lateral escape of radiation. 


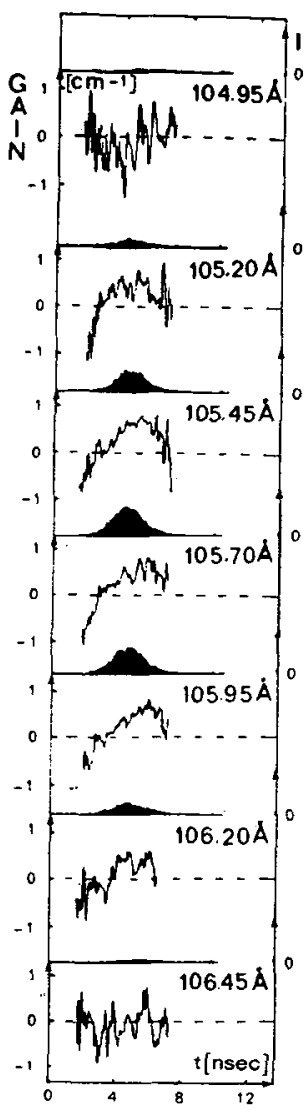

$\mathbf{a}$

Gain measured is found the same, i.e. $3 \mathrm{~cm}^{-1}$ for both transitions $5 f-3 d \quad(105.7 \AA)$ and $4 f-3 d \quad(154.6 \AA)$ in the Rutherford experiment whereas at Palaiseau, if we compare measurements made in the same conditions of plasma length and of laser energy at $0.6 \mathrm{~mm}$ from, the target surface, higher gain has been observed at $154.6 \AA\left(1.5 \mathrm{~cm}^{-1}\right)$ than at $105.7 \AA$ $\left(0.8 \mathrm{~cm}^{-1}\right)$. This latter could be qual itatively more coherent with conclusions of theoretical analyses which

predict comparable populations for both levels and a higher amplification for the $4 \mathrm{f}-3 \mathrm{~d}$ transition at $154.6 \mathrm{~A}$ than for the $5 \mathrm{f}-3 \mathrm{~d}$ at $105.6 \AA$ which is less probable. However calculations show that density of inversions depends of many factors and connexion between both experiments is somewhat difficult since they differ on many points.

OUILOOK TO SHORTER WAVELENGIH. A possible X-ray laser working between $23 \AA$ and $43.5 \AA$ is very interesting for biological purposes. Indeed since water is rather transparent to these wavelengths whereas Carbon is opaque to them one hopes so obtaining microscopic holograms with

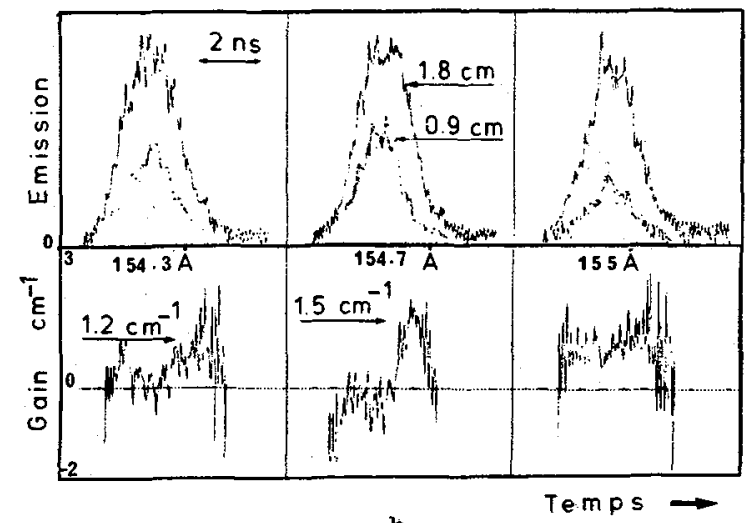

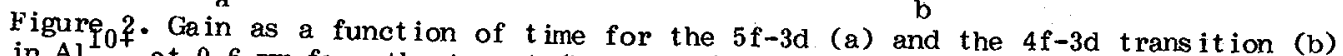
in $\mathrm{Al}$ at $0.6 \mathrm{~mm}$ from the target (Pala iseau).
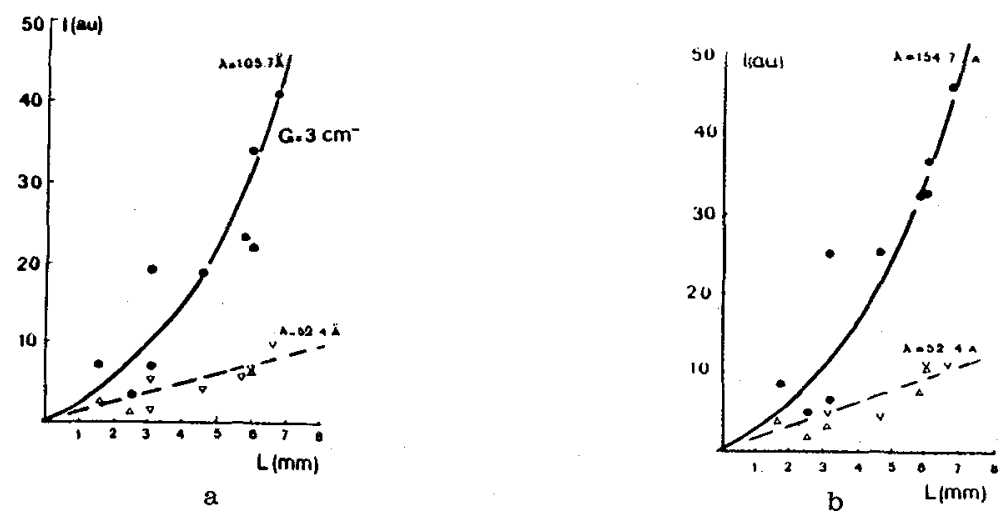

Figure 3. Exponential increase of intensity for the $5 f-3 d(a)$ and the $4 f-3 d$ transition (b) in $\mathrm{Al} 10^{+}$(Rutherford).

good contrast. Considering a given lasing scheme, shorter wavelengths imply to use higher $Z$ elements which will need higher laser flux to be ionized in the proper stafe. Since fluxes necessary for obtaining a gain in $\mathrm{Li}-1$ ike Al are relatively. low $\left(10^{1}\right.$ w $^{\circ} \mathrm{M}^{-2}$ ) this scheme appears to be a good candidate for progress ing towards shorter wavelengths. In this purpose we have planed to study higher $Z$ elements. On the bas is of a theoretical study $16 /$, we have started to investigate the $5 f-3 d 1$ ine in Sulfur at $65.2 \mathrm{~A}$. Prel iminary results concerning a time integrated experiment are presented here on fig.5. A peak of gain is clearly visible on the recording. Taking into 
account the effects of time integration and of experimental width a simulation reveals time resolved gain to be about $1 \mathrm{~cm}^{-1}$. Up to now, no time resolved investigation has been achieved due to difficulties in the fabrication of mass ive sulfur targets able to resist to the sufficiently high number of laser shots necessary to statistics. This number is lower for time integrated measurements.

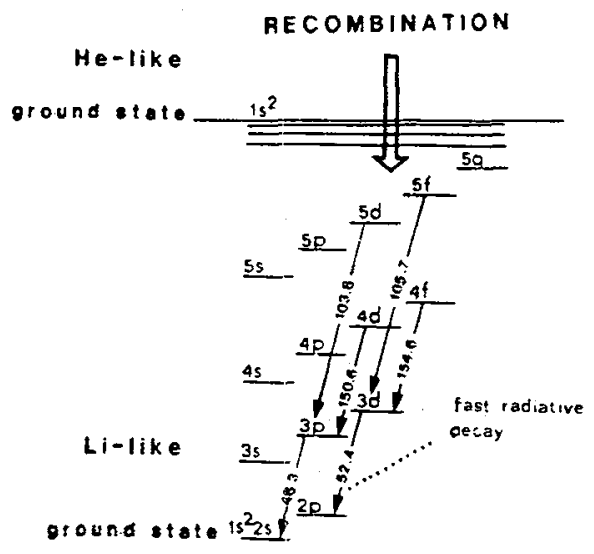

Figure 4. Simplified Lithium-like atomic structure of Al.

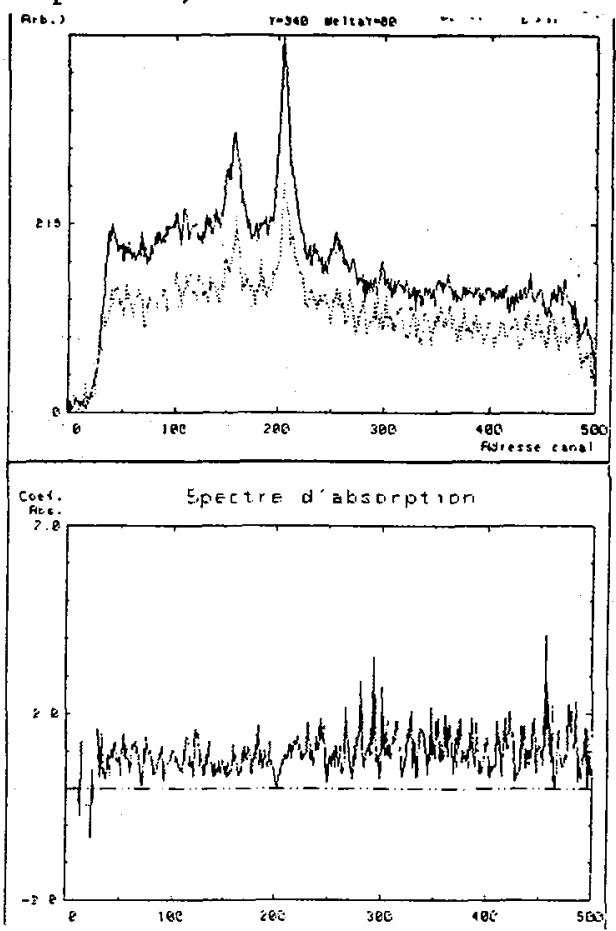

Figure 5. Time-integrated absorption spectrum in a sulfur plasma, 2 cm-long. (5f-3d transition in $\mathrm{S}^{13+}$ at $\left.65.2 \AA\right)$ ).

REFERENCES.

$/ 1 /$ - P. JAAGTE, G. JAMELOOT, A. CARILJON, A. KLISNICK, A. SUREAU and H. GUENNOU, J.O.S.A. B, 4, 563 (1987); (Feature edition on the Generation of Coherent XIJ and Sof $t-X$-ray Radiation).

$12 /$ - H. GUENNOU, A. SUREAU, C. MOLLER, International Colloquium on X-Ray Lasers, Aussois, France, 1986; Journal de phys ique, C6-351, Vol 47 (1986).

$13 /$ - P. JAEGLE, G. JAMELOT, A. CARILLON and C. WEHENKEL, Jpn. J. Appl . Phys . 17, 483 (1978).

$14 /$ - H. GJENNOU and A. SUREAU, Annual Report of Greco "Interaction Laser-Mat ière", Ecole Polytechnique, Pala iseau, France, p. 151 (1979).

151 - A. KLISNICK, H. GJENNOU and J. VIRMONT, Journal de Phys ique, 47, 66351 (1986).

$16 /$ - H. GUENNOU and A. SUREAU, J. Phys . B, 20, 919 (1987).

/7/ - G. JAMELOT, A. KLISNICK, A. CARILLON, B. GAUIHE, P. JAFGLE, Anmual Report of Greco "Interaction Laser-Matière", Ecole Polytechnique, Pala iseau, France (1986).

$18 /$ - G. JAMEIOT, A. KIISNICK, A. CARILION, P. JAEGLE (LSAI, Orsay, France); M. H. KEY, G. KIEHN (RAL, Didcot, UK); O. WILLI, R. SMITH (IC, London, UK); C.REAGAN (qub, Belfast,UK); T. TOMIE (Elect. Lab. Japan); Anmual Report of Greco "Interaction Laser-Mat ière", Ecole Polytechnique, Pala iseau, France (1986). 